\title{
Kapasitif Enkoderler için Sağlam bir Algılayıcı Mekaniği
}

\author{
Emrehan Yavsan ${ }^{1 *}$, Muhammet Rojhat Kara ${ }^{2}$, Mehmet Karal1 ${ }^{1}$, Mehmet Akif Erişmiş ${ }^{3}$ \\ ${ }^{1}$ Necmettin Erbakan Üniversitesi, Mühendislik ve Mimarlık Fakültesi, Mekatronik Mühendisliği Bölümü, Konya, Türkiye (ORCID: 0000-0001-9521-4500) \\ ${ }^{2}$ Karamanoğlu Mehmetbey Üniversitesi, Mühendislik Fakültesi, Elektrik-Elektronik Mühendisliği Bölümü, Karaman, Türkiye (ORCID: 0000-0002-0353-1902) \\ ${ }^{3}$ Necmettin Erbakan Üniversitesi, Mühendislik ve Mimarlık Fakültesi, Elektrik-Elektronik Mühendisliği Bölümü, Konya, Türkiye (ORCID: 0000-0001-6837-2087)
}

( $1^{\text {st }}$ International Conference on Computer, Electrical and Electronic Sciences ICCEES 2020 - 8-10 Ekim 2020)

(DOI: $10.31590 /$ ejosat.801957)

ATIF/REFERENCE: Yavşan, E., Kara, M.R., Karalı, M. \& Erişmiş, M.A. (2020). Kapasitif Enkoderler için Sağlam bir Algılayıcı Mekaniği. Avrupa Bilim ve Teknoloji Dergisi, (Özel Sayı), 47-53.

\section{$\ddot{O} z$}

Kapasitif enkoder teknolojisi manyetik ve optik enkoder teknolojilerine kıyasla daha güncel ve günümüzde halen geliştirilmekte olan bir açısal pozisyon algılayıcı teknolojisidir. Çeşitli özelliklerde ve farklı bileşenlere sahip kapasitif enkoderler bulunmaktadır. Yenilikçi ve yüksek performanslı kapasitif bir enkoderin geliştirilebilmesi için mevcut kapasitif enkoderlerin ayrıntılı bir şekilde irdenlenmesi ve sınıflandırılması gerektiğinden bu çalışmada genel bir kapasitif enkoder mimarisi tanımlanarak kapasitif enkoderler için detaylı bir sınıflandırma verilmiştir. Sunulan mimari; sinyal işleme ön devresi, algılayıcı mekaniği ve sinyal işleme son devresinden oluşmaktadır. Sinyal işleme ön devresi kapasitif enkoderin tetikleme sinyal devresini, sinyal işleme son devresi kapasitif enkoderin demodülasyon devresini içermektedir. Burada sağlam bir algılayıcı mekaniğin belirlenebilmesi için kapasitif enkoderler detaylı bir șekilde sınıflandırılmıștır. Sınıflandırma ișlemi kapasitif enkoderlerin plaka sayılarına, plakalar üzerine yerleștirilen elektrot dizilişlerine ve rotor plakaların malzemelerine göre yapılmıştır. Sınıflandırma sonucunda sağlam bir algılayıcı mekaniğine karar verilmiştir. Algılayıcı mekaniğindeki bileşenler çeşitli analizlerle belirlenip bilgisayar destekli tasarım programlarıyla tasarlanmıştır. Tasarlanan mekanik bileşenler üretildikten sonra sunulan algılayıcı mekaniği kurulmuştur. Kurulan algılayıcı mekaniği için de bir ön tasarım süreci işletilmiştir. Algılayıcı mekaniği kurulduktan sonra uygun fiyatlı bir test düzeneğinde test edilmiştir. Bu çalışmayla, geliştirilmekte olan yenilikçi ve yüksek performanslı kapasitif enkodere sağlam bir algılayıcı mekaniği kazandırılmıştır.

Anahtar Kelimeler: Kapasitif Rotary Enkoder, Kapasitif Ölçüm, Açı Ölçümü, Enkoder Mekaniği, Kapasitif Sensör Mekaniği.

\section{A Robust Sensor Mechanics for Capacitive Encoders}

\begin{abstract}
Capacitive encoder technology is an angular position sensing technology that is more current and still being developed today compared to magnetic and optical encoder technologies. Capacitive encoder technologies with various properties and different components are available. Existing capacitive encoders in the literature need to be classified extensively to develop an innovative and high performance capacitive encoder. In this study, a general capacitive encoder architecture was defined and capacitive encoders were classified in detail. The presented capacitive encoder architecture consists of the signal processing front-end circuit and sensor mechanics of the capacitive encoder. The signal processing front circuit contains the excitation signal circuit of the capacitive encoder and the signal processing end circuit includes the demodulation circuit of the capacitive encoder. In this study, capacitive encoders were classified in detail in order to achieve a robust sensor mechanics. The classification process was carried out according to the number of plates of capacitive encoders, the electrode arrays placed on the plates and the materials of the rotor plates. A robust sensor mechanics was decided by the classification process. After reaching the sensor mechanical components through various analyzes, these components were designed using computer-aided design programs. After the designed mechanical components were produced, a
\end{abstract}

${ }^{*}$ Sorumlu Yazar: Necmettin Erbakan Üniversitesi, Mühendislik ve Mimarlık Fakültesi, Mekatronik Mühendisliği Bölümü, Konya, Türkiye, ORCID: 0000-0001-9521-4500, eyavsan@erbakan.edu.tr 
robust sensor mechanics was established. A preliminary design process was also used for the proposed robust sensor mechanics. The designed sensor mechanics was tested in a low-priced test setup after the realization. As a result of this study, a robust sensor mechanics has been provided to the innovative and high performance capacitive encoder under development.

Keywords: Capacitive Rotary Encoder, Capacitive Measurement, Angle Measurement, Encoder Mechanics, Capacitive Sensor Mechanics.

\section{Giriş}

Enkoderlerler açı ölçümünde kullanılan pozisyon algılayıcılarıdır. Bu açısal pozisyon algılayıcıların içerisinde mekanik olarak değişen açı değeri, dijital bir sinyal üzerine aktarılarak algılayıcı çıkışına iletildiğinden bu tip algılayıcıların mekanik birer analogdijital dönüştürücü olarak görev yaptıkları söylenebilir. Manyetik, optik ve kapasitif enkoder teknolojileri bulunmaktadır. Bunlar arasında esnek kullanıma en yatkın olanı kapasitif enkoder teknolojisidir. Esneklik, algılayıcı mekaniğin çeşitli şekillerde üretilebilmesinden kaynaklanır.

Kapasitif bir algılayıcıyla ölçülen fiziksel büyüklük, kapasitansın çeşitli şekillerde değiştirilebilmesiyle ölçülebilir. Buradaki en önemli kriter; ölçülecek fiziksel büyüklüğün Denklem 1'deki temel kapasitans parametreleriyle ilişkilendirilmesidir.

$$
C=\varepsilon \frac{A}{d}
$$

burada $\boldsymbol{C}$ kapasitansı, $\boldsymbol{\varepsilon}$ dielektrik sabitini, $\boldsymbol{A}$ kapasitansı oluşturan plakaların örtüşme alanlarını ve $\boldsymbol{d}$ plakalar arasındaki mesafeleri temsil eder. Kapasitif enkoder plakaları arasındaki kapasitansın bu 3 parametreden biriyle değiştirilmesi sonucunda çeştli algılayıcı mekanikleri oluşturulabilir. Bu yolla yüksek çözünürlük ve düşük boyutlarda çeşitli mekaniklere sahip kapasitif enkoderler geliştirilmiştir [1-3]. Fakat algılayıcı mekaniklerin kararlı ve sağlam olması gerekmektedir. Burada minyatürize ve yüksek çözünürlüklü bir kapasitif enkodere kararlı bir algılayıcı mekaniği kazandırmak için atılan adımlar ayrıntılarıyla verilmeye çalışıllmıştır.

Sağlam bir algılayıcı mekaniğiyle kapasitif enkoderlerdeki hataların çoğu ciddi oranta azaltılabilir. Wolffenbuttel ve Kampen sundukları algılayıcı mekaniğindeki plaka desenlerini değiştirerek aynı mekanik üzerinden ölçülen açı verisindeki hataları azaltmışlardır [4]. Mohammed ve Rehman da benzer bir çalışma yaparak sundukları kapasitif enkoderin rotor plaka şekil ve desenini geliştirerek daha önce sundukları algılayıcı prototipinden daha iyi sonuçlar elde ettiklerini göstermişlerdir [5].

Zangl ve Bretterklieber kapasitif algılayıcıların plaka şekillerinin belirlenmesi üzerine bir çalışma yapmışlardır. Benzetim ortamında iki farklı kapasitif algılayıcının en iyi rotor şekillerine ulaşmaya çalışmışlardır. Fakat bu çalışmada sadece rotor şekline yoğunlaşılmıştır. Algılayıcı mekaniklerin tamamı çalışmaya dahil edilebilir. Yinede bu tip çalışmaların azlığı göz önüne alındığında kapasitif algılayıcı geliştirme sürecinde doğru adımların nasıl atılması gerektiğini gösteren kıymetli çalışmalardandır [6].

Zheng ve arkadaşları, herhangi bir yazılımsal hata minimizasyonu algoritması kullanmadan algılayıcı mekaniklerinde yaptıkları iyileştirmelerle enkoderin doğrusal olmama hatasını indirgemişlerdir [7]. Kapasitif enkoder çıkış sinyalindeki hataların benzer şekilde algılayıcı mekanikleri üzerinden giderildiği buna benzer bir kaç çalışma daha bulunmaktadır $[8,9]$.

Bu çalışmaların tamamı sağlam bir algılayıcı mekaniğin kapasitif enkoderler için ne kadar önemli bir bileşen olduğunu gösteren değerli çalışmalardır. Fakat kapasitif enkoder gelişiminde algılayıcı mekaniğin nasıl belirlendiğiyle ilgili çalışma sayısı yok denecek kadar azdır [10]. Varolan az sayıda çalışmanın da güncellenmeye ihtiyacı vardır.

Kapasitif enkoderlerle ilgili çalışmalar incelendiğinde kapasitif enkoderlerin elektriksel bir sinyal işleme devresiyle algılayıcı mekaniğin birleşiminden oluştuğu görülmektedir. Sinyal işleme devresinde genel olarak kapasitif enkoderin çalıştırılmasında kullanılan uyartım sinyallerin üretimi, enkoder çıkış sinyallerinin demodülasyonu ve açı dönüşümü yapılmaktadır. Buradan kapasitif enkoderler için Şekil 1'deki gibi bir genel mimari çıkartılabilir.

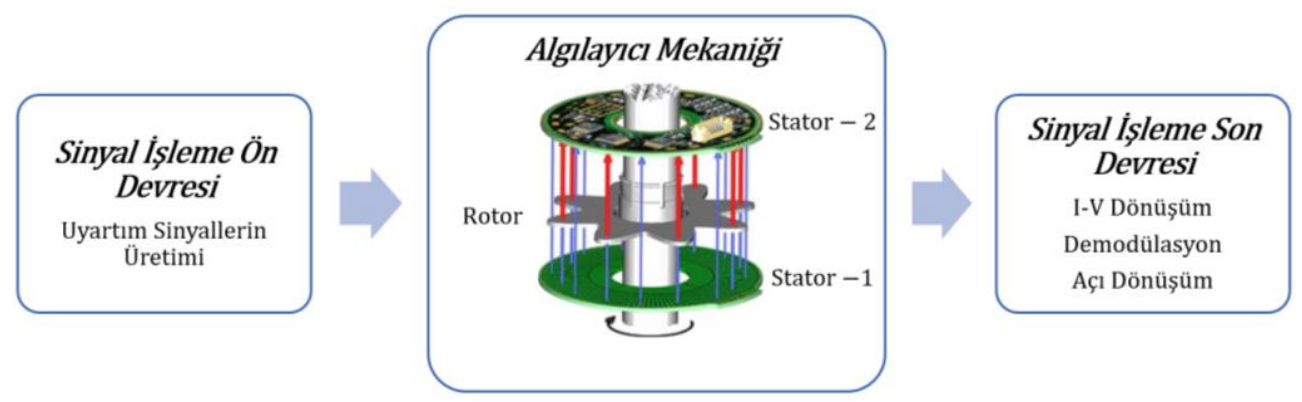

Şekil 1. Kapasitif enkoder mimarisi [11] 
Kapasitif enkoderin hareketsiz stator plakalarına uyartım sinyalleri uygulandığında enkoder plakaları arasında rotor plakasının dönüşüyle orantılı kapasitanslar oluşacaktır. Bu kapasitanslar, enkoder plakaların örtüşme alanlarıyla değişir. Kapasitanslardan geçen sinyallerin stator plakaları üzerinden alınması ve uygun demodülasyon yöntemiyle demodüle edilip açı verisine dönüştürülmesi sonucunda rotor plakasının açısal pozisyonuna ulaşılabilir.

Şekil 1'de gösterilen algılayıcı mekaniğindeki en ufak değişim tüm enkoder mimarisini etkileyecektir. Bu nedenle algılayıcı mekaniği sağlam kurulmalı ve mekanik üretildikten uygulanabilirlikten uzaklaşmadan test edilmelidir. Bu çalışmada yenilikçi ve yüksek performanslı kapasitif bir enkoder için sağlam bir algılayıcı mekaniği kurulmuştur. Kurulan mekanik; düşük maliyetli ve enkoderin uygulanabilirliği düşünülerek sıfırdan oluşturulmuş bir test düzeneğinde test edilmiştir.

\section{Materyal ve Metot}

\subsection{Kapasitif Enkoderlerin Detaylı Sınıflandırılması}

Algılayıcı mekaniğin oluşturulabilmesi için kapasitif enkoderler; plakalarının sayısı ve yerleşimi, rotor plakasına temasın olup olmaması, rotorun iletkenliği, şekli ve deseni ile sinyal işleme devresi için tercih edilen algılama yöntemine göre incelenmiş ve altı farklı sınıfa ayrılmıştır.

\subsubsection{Tip-1 Kapasitif Enkoder}

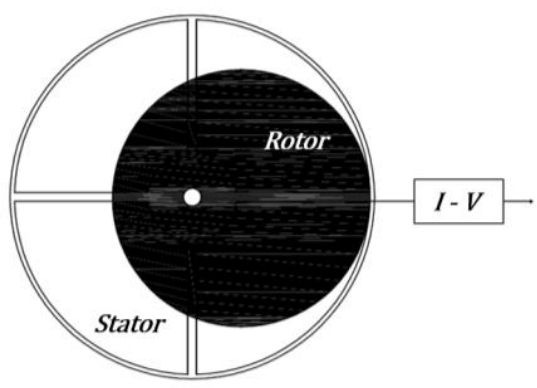

Şekil 2. Tip-1 enkoder [12]

Şekil 2'deki tip-1 enkoder, 1 adet stator ve 1 adet rotor plakasından oluşan 2 katmanlı kapasitif enkoder tipidir. Stator plakası üzerine yerleştirilmiş olan çeyrek daire şeklindeki her bir verici elektroda aralarında $90^{\circ}$ faz farkı bulunan ve eş frekanslı tetikleme sinyalleri uygulanabilir.

Plakalar arasında oluşan kapasitans üzerinden geçen akım, rotor plakasını kaplayan toplayıcı elektrot üzerinden alınarak akımgerilim (I-V) dönüştürücü devresiyle enkoder çıkış gerilimine dönüştürülmektedir. Bu tipte olduğu gibi toplayıcı elektrotların rotor üzerinde bulunduğu her tip için rotora temas söz konusudur. Rotora fiziksel bir temasın olması genelde istenmeyen bir durumdur ve rotorun bağımsız bir şekilde dönebilmesi istenir. Aksi halde sürtünmelerden kaynaklı sorunlar meydana gelebilecek ve algılayıcı doğruluğu olumsuz yönde etkilenecektir.

Kapasitif enkoderler için tek ya da iki yüzü de iletken rotorlar kullanılabilir. Şekil 2'de merkezi kaydırılmış daire şeklindeki tek kutuplu rotor tercih edilmiştir. Fakat farklı desenlerdeki çok kutuplu rotorlar da tercih edilebilir. Çok kutuplu bir rotorun tercih edilmesi durumunda uyartım elektot sayısının kutup sayısıyla orantılı olarak artacağı unutulmamalıdır. Bu artış, rotorun her kutbu için özdeş uyartım elektrotlardan oluşan 1 adet uyartım elektrot grubu şeklindedir. Tip - 1 enkoder ile bu çalışmada sunulan diğer tiplerden de görüleceği üzere rotorların tek kutbunun karşısında 4 adet özdeş elektrottan oluşan 1 adet elektrot grubu bulunmaktadır.

Tip-1 enkoderde uyartım sinyalleri stator üzerindeki çeyrek daire dilimli ve aynı isimli uyartım elektrotlara uygulandıktan sonra plakalar arasındaki kapasitans oluşumu stator üzerindeki uyartım elektrotlardan rotor üzerindeki toplayıcı elektrotlara doğru olur.

\subsubsection{Tip-2 Kapasitif Enkoder}

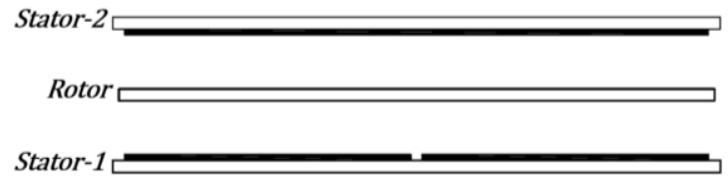

Şekil 3. Tip-2 enkoder [2, 9] 
Şekil 3'te verilen tip-2 enkoder, 2 adet stator ve 1 adet rotor plakasından oluşan 3 katmanlı kapasitif enkoder tipidir. 3 katmanlı yapısından dolayı rotor eksenindeki bozulmalara ve rotor eğimine karşı 2 katmanlı tiplere nazaran daha dirençlidir. Burada uyartım elektrotları alt kısımda bulunan stator plakası üzerine yerleştirilmişken tek parça halindeki toplayıcı elektrot, üst kısımdaki stator üzerindedir. Plakalar arasında oluşan kapasitans üzerinden geçen akım, toplayıcı elektrot üzerinden alınacağından rotora temas söz konusu değildir. Bu tipte dielektrik rotor kullanılmıştır.

Uyartım sinyalleri verici elektrotlara uygulandıktan sonra plakalar arasındaki kapasitans oluşumu bu tip için verici elektrotlardan toplayıcı elektroda doğrudur.

\subsubsection{Tip-3 Kapasitif Enkoder}

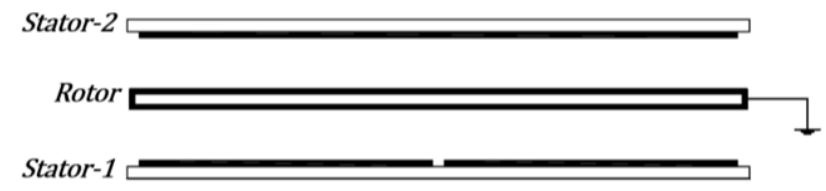

Şekil 4. Tip-3 enkoder [13]

Şekil 4'te 2 adet stator ve 1 adet rotor plakasından oluşan 3 katmanlı tip-3 enkoder gösterilmiştir. Tip-2 gibi bu tip enkoder de rotor eğimine karşı duyarsızdır. Bu tipte uyartım elektrotları alt kısımda bulunan stator plakası üzerine yerleştirilmişken tek parça halindeki toplayıcı elektrot, üst kısımdaki stator üzerindedir.

Enkoder plakaları arasında oluşan kapasitans üzerinden geçen akım, toplayıcı elektrot üzerinden alınmasına rağmen topraklama işleminden dolayı rotora temas söz konusudur. Tip-3 enkoderde her iki yüzü iletken rotor kullanılmış olup, rotor topraklanmıştır. Yüzler arasında elektriksel iletim vardır.

Uyartım sinyalleri, uyartım elektrotlara uygulandıktan sonra plakalar arasındaki kapasitans oluşumu bu tip için verici elektrotlardan alıcı elektroda doğrudur.

\subsubsection{Tip-4 Kapasitif Enkoder}

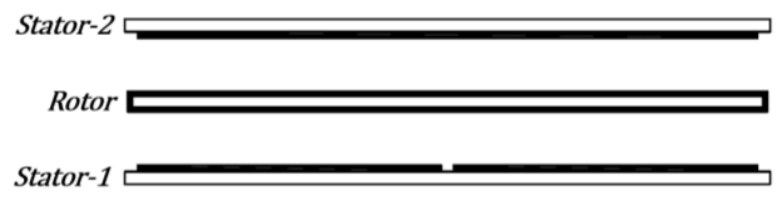

Şekil 5. Tip-4 enkoder [14]

Şekil 5'te verilen tip-4 enkoder, 2 adet stator ve 1 adet rotor plakasından oluşan 3 katmanlı kapasitif enkoder tipidir. Diğerlerine göre daha yaygın olarak çalışılan bir tiptir. Bu tipteki uyartım elektrotları alt kısımda bulunan stator plakası üzerine yerleştirilmişken tek parça halindeki toplayıcı elektrot, üst kısımdaki stator üzerindedir. Plakalar arasında oluşan kapasitans üzerinden geçen akım, toplayıcı elektrot üzerinden alınacağından rotora temas yoktur. İki yüzü iletken rotor kullanılmış olup rotorun her iki yüzü arasında elektriksel iletim vardır.

Uyartım sinyalleri aynı isimli uyartım elektrotlarına uygulandıktan sonra plakalar arasındaki kapasitans oluşumu uyartım elektrotlardan rotor yüzeyine kaplanmış olan elektroda, oradan da alıcı elektroda doğrudur. Burada rotorun aynı deseni içeren özdeş yüzlerden oluşması gerekmez. Yüzlerden sadece birinin desen içermesi yeterlidir. Önemli olan rotor yüzleri arasında elektriksel iletimin olmasidir.

\subsubsection{Tip-5 Kapasitif Enkoder}

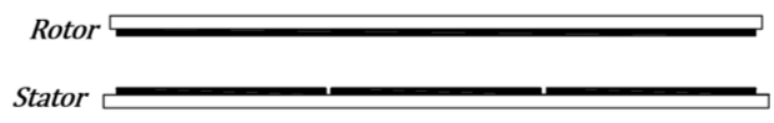

Şekil 6. Tip-5 enkoder [7]

Şekil 5'teki enkoder, 1 adet stator ve 1 adet rotor plakasından oluşan 2 katmanlı tip-5 kapasitif enkoderdir. Burada uyartım elektrotları stator plakasının dış kısmına yerleştirilmişken tek parça halindeki toplayıcı elektrot, stator plakasının iç kısmına 
yerleştirilmiştir. Tip-5 enkoder plakaları arasında oluşan kapasitans üzerinden geçen akım, toplayıcı elektrot üzerinden alınacağından rotora temas yoktur ve tek yüzü iletken rotor kullanılmıştır.

Tip-5 enkoderlerde diğer tiplerden farklı olarak toplayıcı ve uyartım elektrotlara ilaveten rotor plakası üzerinde bağlayıcı ve yansıtıcı elektrotlar bulunmaktadır. Toplayıcı ve uyartım elektrotlar birbirlerinden izoleyken bağlayıcı ve yansıtıcı elektrotlar iletim halindedir. Bu nedenle bağlayıcı ve yansıtıcı elektrotlar tek parça şeklinde düşünülebilirler.

Bağlayıcı elektrot, uyartım elektrotların tam karşısında bulunurken yansıtıcı elektrot ise toplayıcı elektrodun tam karşısında bulunmaktadır. Uyartım sinyalleri uygulandıktan sonra plakalar arasındaki kapasitans oluşumu; uyartım elektrotlarından bağlayıcı elektroda, oradan yansitıcı elektroda, yansitıcı elektrottan da toplayıcı elektroda şeklindedir. Tip-5 ve benzeri kapasitif enkoderlerde kullanılan bağlayıcı elektrotlar, genellikle rotor desenini oluşturan elektrotlardır.

\subsubsection{Tip-6 Kapasitif Enkoder}

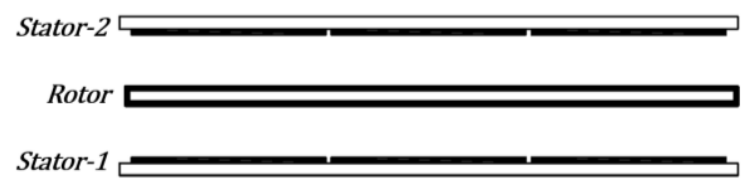

Şekil 7. Tip-6 enkoder. Bu çalışmada sunulan sağlam algılayıcı mekaniği bu tipten türetilmiştir.

Şekil 7'deki tip-6 enkoder, 2 adet özdeş stator ve her iki yüzünde aynı deseni içeren 1 adet rotor plakasından oluşan 3 katmanlı kapasitif enkoder tipidir. Bu enkoder tip-5 enkoderin simetrisi alınarak oluşturulduğundan tip- 5 'e göre rotor eğimine karşı daha duyarsizdır.

Tip-6'daki uyartım elektrotları, stator plakalarının dış kısmına yerleştirilmişken tek parça halindeki toplayıcı elektrotlar, stator plakalarının iç kısmına yerleştirilmiştir. Buradaki plakalar arasında oluşan kapasitans üzerinden geçen akım, toplayıcı elektrotlar üzerinden alınacağından rotora temas yoktur.

Tip-6 enkoderde iki yüzü iletken rotor kullanılmış olup rotorun her iki yüzü arasında elektriksel iletim söz konusudur. Bu tipteki enkodere uyartım sinyalleri uygulandıktan sonra enkoder plakaları arasında; uyartım elektrotlarından bağlayıcı elektrotlara, oradan da yansıtıcı elektrotlar üzerinden toplayıcı elektrotlara şeklinde bir kapasitans oluşumu gözlenmektedir. Bu çalışmada sunulan enkoder tiplerindeki kapasitans oluşumları, parazitik kapasitanslar ihmal edilerek verilmiştir.

\subsection{Algılayıcı Mekaniğin Oluşturulması}

Bu çalışmada sağlam bir algılayıcı mekaniğine ulaşmak için sunulan detaylı sınıflandırılma sonucunda 2 katmanlı yapılara göre daha dirençli olan tip-6 kapasitif enkoder türevi bir yapı tercih edilmiştir. Tercih edilen 3 katmanlı enkoderin rotor plakasının belirlenmesi için çeşitli analizler ve değerlendirmeler yapılmıştır [15]. Yapılan bu çalışmaların sonucunda Şekil 8'deki plaka tasarımların kullanılmasına karar verilmiştir.

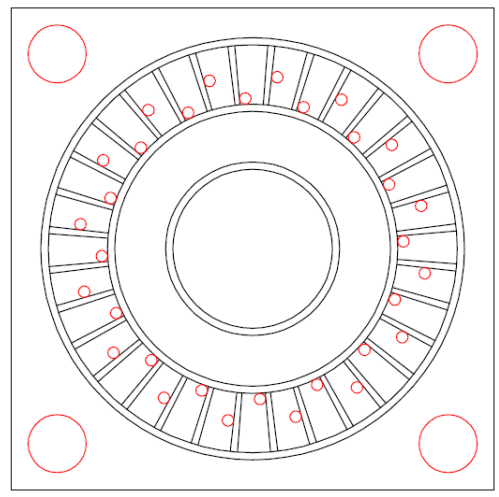

(a) stator-1

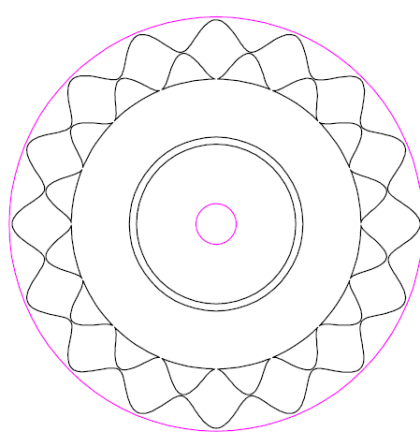

(b) rotor

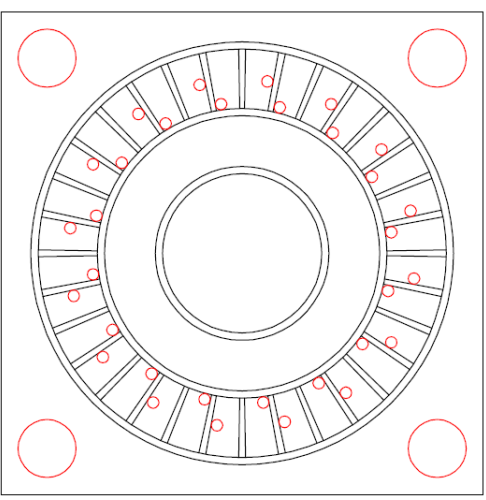

(c) stator-2

Şekil 8. Sunulan kapasitif algılayıcı mekaniğinde kullanılacak olan plakalar.

Şekil 8'de verilen plaka tasarımları üretildikten sonra Şekil 9a'daki mekanik tasarım, Şekil 9b'de kurulmuştur. Kurulan enkoder mekaniği düşük maliyetle ve laboratuvar imkanlarında oluşturulan Şekil 9c'deki test düzeneğinde test edilmiştir. 


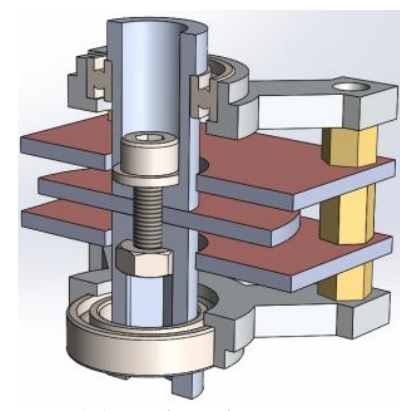

(a) mekanik tasarım

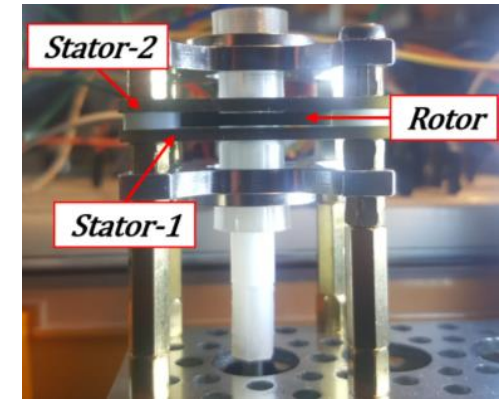

(b) mekanik kurulum

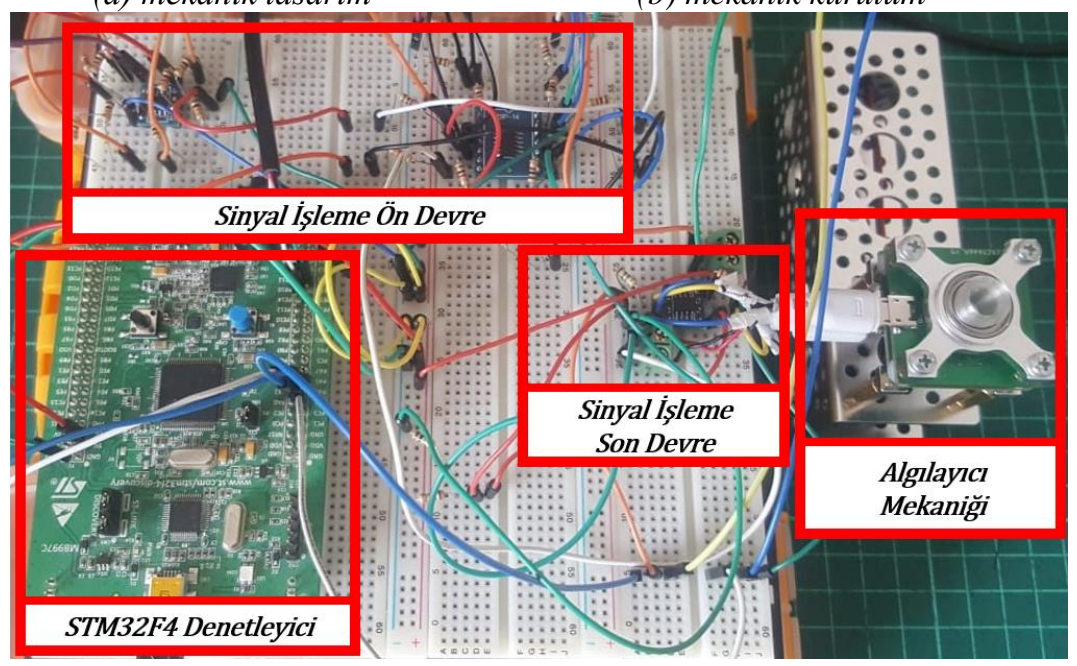

(c) test

Şekil 9. Săglam bir kapasitif enkoder mekaniğin (a) tasarımı, (b) kurulumu ve (c) testi

\section{Sonuç}

Kapasitif enkoder çalışmalarında algılayıcı mekaniğin tüm kapasitif enkoder mimarisini şekillendirdiği ve mimariyi doğrudan etkilediği görülmektedir. Buna rağmen özellikle kapasitif enkoderler için algılayıcı mekaniğin, hangi parametrelerle ve nasıl belirlendiğiyle ilgili çalışmalar yok denecek kadar azdır.

$\mathrm{Bu}$ çalışmada kapasitif enkoder geliştirme süreci özellikle mekanik açıdan ayrıntısıyla ele alınmış ve detaylı bir inceleme yapılmıştır. Yapılan incelemeler sonucunda sağlam bir kapasitif enkoder mekaniği elde edilmiş ve gerçekleştirilmiştir. Sunulan sağlam enkoder mekaniği laboratuvar ortamında gerçekleştirilen uygun fiyatlı bir test düzeneğinde test edilmiştir.

$\mathrm{Bu}$ çalışmayla geliştirilmekte olan yenilikçi ve yüksek performanslı kapasitif bir enkodere sağlam bir algılayıcı mekaniği ve altyapı kazandırılmış olup sunulan test düzeneğin geliştirilmesine devam edilmektedir.

\section{Teşekkür}

Bu çalışma "Yenilikçi ve Yüksek Performanslı Kapasitif Rotary Enkoder Geliştirilmesi" başlıklı NEÜ BAP birimi tarafindan 191419007 proje numarasıyla, TÜBİTAK tarafindan 2211-C kapsamında 1649B031907024 burs başvuru numarasıyla desteklenen doktora çalışmasından bir bölümün derlenip detaylandırılmasıyla hazırlanmıştır.

\section{Kaynakça}

[1] Krklješ, D., Vasiljević, D., \& Stojanović, G. (2014). A capacitive angular sensor with flexible digitated electrodes. Sensor Review.

[2] Karali, M., Karasahin, A. T., Keles, O., Kocak, M., \& Erismis, M. A. (2018). A new capacitive rotary encoder based on analog synchronous demodulation. Electrical Engineering, 100(3), 1975-1983.

[3] Fu, Y., Fan, W., Jin, H., \& Chen, Q. (2020). A new capacitance angle sensor of concentric ring multi-layer differential. Measurement, 158, 107625.

[4] Wolffenbuttel, R. F., \& Van Kampen, R. P. (1991). An integrable capacitive angular displacement sensor with improved linearity. Sensors and Actuators A: Physical, 27(1-3), 835-843.

[5] Mohammed, E. B., \& Rehman, M. (2003). Digital capacitive angular-position sensor. IEE Proceedings-Science, Measurement and Technology, 150(1), 15-18. 
[6] Zangl, H., \& Bretterklieber, T. (2004, October). Rotor design for capacitive sensors. In SENSORS, 2004 IEEE (pp. 520-523). IEEE.

[7] Zheng, D., Zhang, S., Wang, S., Hu, C., \& Zhao, X. (2014). A capacitive rotary encoder based on quadrature modulation and demodulation. IEEE Transactions on Instrumentation and Measurement, 64(1), 143-153.

[8] Kimura, F., Gondo, M., Yamamoto, A., \& Higuchi, T. (2009, November). Resolver compatible capacitive rotary position sensor. In Industrial Electronics, 2009. IECON'09. 35th Annual Conference of IEEE (pp. 1923-1928). IEEE.

[9] Das, S., Sarkar, T. S., \& Chakraborty, B. (2018). Simple approach to design a capacitive rotary encoder. IET Science, Measurement \& Technology, 12(4), 500-506.

[10] Brasseur, G. (2003). Design rules for robust capacitive sensors. IEEE Transactions on Instrumentation and Measurement, 52(4), $1261-1265$.

[11] Zheng, D., Zhang, S., Zhang, Y., \& Fan, C. (2012, July). Application of CORDIC in capacitive rotary encoder signal demodulation. In 2012 8th IEEE International Symposium on Instrumentation and Control Technology (ISICT) Proceedings (pp. 61-65). IEEE.

[12] Netzer, Y., 2002, U.S. Patent No. 6,492,911. Washington, DC: U.S. Patent and Trademark Office.

[13] Netzer, Y. Rotary Electric Encoder Technology.

[14] Ferrari, V., Ghisla, A., Marioli, D., and Taroni, A., 2006, Capacitive angular-position sensor with electrically floating conductive rotor and measurement redundancy. IEEE transactions on instrumentation and measurement, 55(2), 514-520.

[15] Yavsan, E., Karali, M., Gokce, B., \& Erismis, M. A. (2020, June). The Effect of Rotor Plates on Capacitive Measurement in Capacitive Encoders. In 2020 International Congress on Human-Computer Interaction, Optimization and Robotic Applications (HORA) (pp. 1-4). IEEE. 